\title{
THE PUPAL WINGS OF HEPIALUS THULE.
}

\author{
By Alex. D. MacGillivray, \\ University of Illinois, Urbana, Illinois.*
}

The adult wings of the different species of the genus Hepialus are of particular interest because they show such a generalized condition. They approximate the closest to the hypothetical wing type of Comstock and Needham of any insect's wings with which I am acquainted. This hypothetical type is supposed to show the number and arrangement of the longitudinal veins as they existed in the primitive insect's wing. These authors have shown that a study of the arrangement of the tracheæ preceding the formation of the veins in developing wings throws much light on the homology of the veins of the adult wing. Many developing wings of Lepidoptera have been studied and figured, but so far as I am aware no investigator has studied and figured the developing wing veins of a species of Ilepialus. It was my good fortune, through the kindness of Professor J. M. Swaine of MacDonald College, Quebec, Canada, to obtain pupæ of Hepialus thule hardened in formol in the right stage for a study of the developing wing veins. These specimens showed not only the trachea, which are represented as black lines on the accompanying figure, but also the veins, which are represented as white bands. Unfortunately nothing could be determined as to the arrangement of the tracheæ after they left the veins and entered the body. The various veins will be taken up in order.

Costa.-The costa can be traced as a distinct, unbranched vein in both wings a short distance within the costal margin. A trachea was found only in the costa of the front wings and this was only a mere stub.

Subcosta.-The subcosta shows as a two-branched vein, identical in form with the subcosta of the hypothetical type. The tracheal stem of subcosta is distinct and in the front wing branched midway between the base of the wing and the point of separation of stubcosta into $\mathrm{Sc}_{1}$ and $\mathrm{Sc}_{2}$, though in the hind wings the point of branching of the trachea is much nearer the point of separation of the two branches of subcosta. The

\footnotetext{
*Contribution from the Entomological Laboratories of the University of Illinois, No. 30.
} 
tracheal branch supplying $\mathrm{Sc}_{1}$ is much weaker than that extending through $\mathrm{Sc}_{2}$. The preservation of both branches of subcosta is peculiar to the Jugatæ among the Lepidoptera. In the Hepialidæ, this condition differs with the different species; in some species they are both well preserved, in others the portion representing the free part of $\mathrm{Sc}_{1}$ is sometimes present in both wings, sometimes present in the front wing and wanting in the hind wing or vice versa, or it may be entirely wanting in both wings, while in still other species no trace of it is ever found. The portion of subcosta always preserved is the long, straight stem representing $S c_{2}$, so that if we may judge from the form of the vein preserved and the decadent condition of the trachea of $S_{1}$, as shown here, the tip of the subcosta as preserved throughout the higher Lepidoptera must be $\mathrm{Sc}_{2}$.

Humeral Cross-Vein. - The humeral cross-vein is usually preserved in the Hepialidæ. It is distinct in this species and located in its usual place between costa and subcosta near the base of the wing.

Radius.-The radius, both so far as the tracheæ and the developing veins are concerned, consists of five branches. A basal stem dividing dichotomously into an unbranched vein, $R_{1}$, and a stem which divides dichotomously into $R_{2}+_{3}$ and $R_{4}+_{5}$. Each of these in turn divide dichotomously, the anterior into $R_{2}$ and $R_{3}$ and the posterior into $R_{4}$ and $R_{5}$. The number of branches and their method of dividing is identical with the hypothetical type. The radius of the hind wings of Hepialus as is common in the Jugatæ, contains as many branches as the radius of the front wings.

Media.-The media of both wings is similar in form and consists of three branches. The median trachea of each wing lies in the same vein cavity as the radial trachea at the proximal end of the wing. They extend along side by side for some distance, then the medial trachea bends away from the radial trachea, and pass into the median vein cavity. The median tracheæ branch dichotomously near the base of each wing, the anterior branch from this dichotomy after a short distance divides again dichotomously into $M_{1}$ and $M_{2}$. The posterior branch from the first dichotomy passes unbranched directly to the wing margin. This branch of media in the hypothetical type gives rise to $M_{3}$ and $M_{4}$. None of the pupal wings of Hepialus examined gave indication of smaller 
branches arising from this trachea. The cross-veins are all without tracheæ as is the usual condition in generalized wings. The posterior branch arising at the first dichotomy of media in IIepialus is undoubtedly the homologue of the posterior branch at the first dichotomy of media of the hypothetical type. This branch in the hypothetical type divides dichotomously

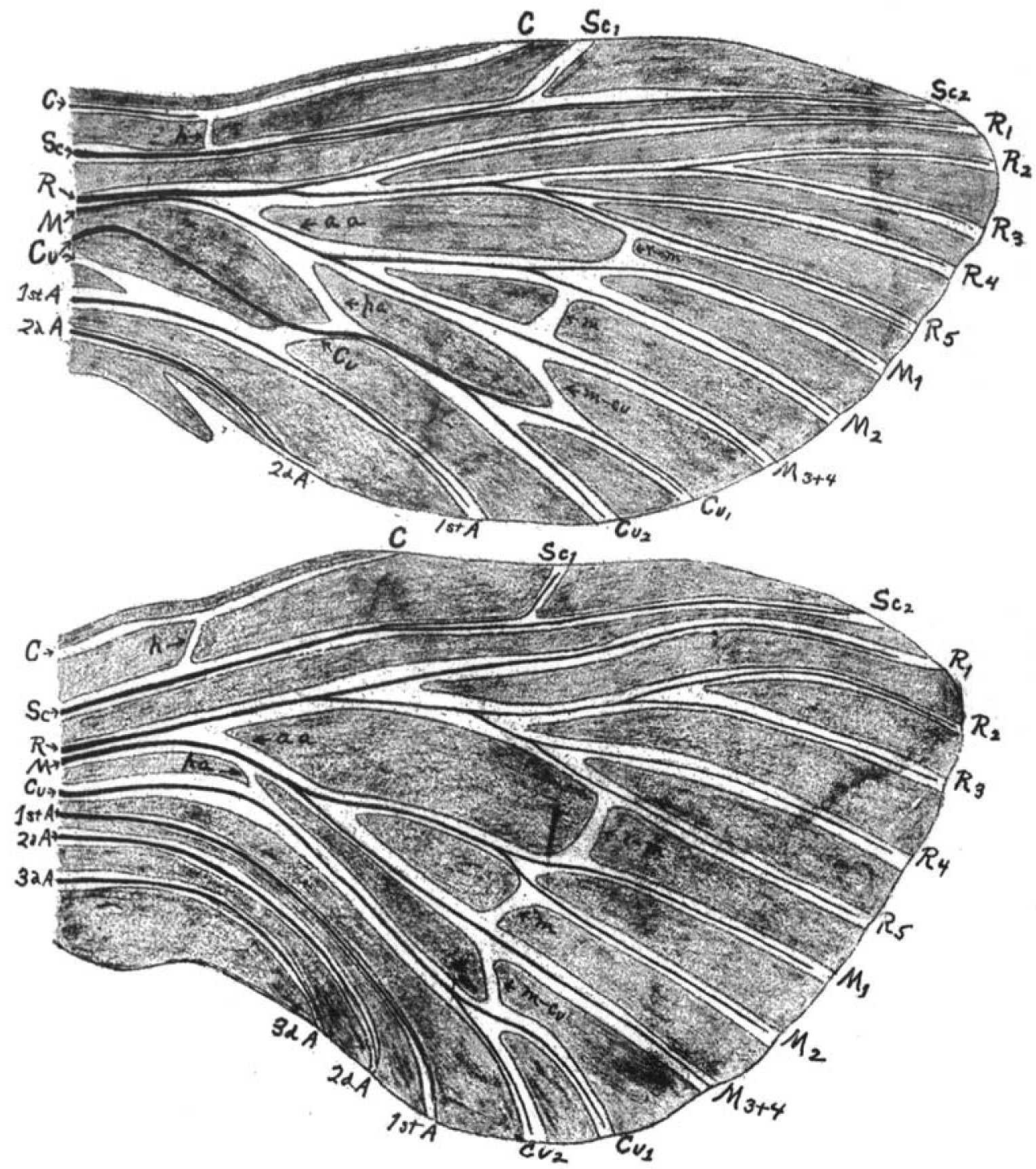

Fig. 1. Hepialus thule, pupal wings. 
into $\mathrm{M}_{3}$ and $\mathrm{M}_{4}$, so that this branch in Hepialus must represent $\mathrm{M}_{3}$ and $\mathrm{M}_{4}$ or as it is here labelled, $\mathrm{M}_{3}+_{4}$. The position of the branch $\mathrm{M}_{4}$ in the Lepidoptera has not been definitely placed. Comstock and Needham figure the wings of Sthenopis, in the hind wing of which there is an extra branch on $\mathrm{Cu}_{1}$, which they label as $\mathrm{M}_{4}$. This would mean, if this interpretation is correct, that $\mathrm{M}_{4}$ is coalesced with $\mathrm{Cu}_{1}$ in the higher Lepidoptera. The wings figured are of a species in which $\mathrm{Cu}_{1}$ is usually unbranched. The specimen figured is undoubtedly an abnormal specimen so far as the branching of $\mathrm{Cu}_{1}$ is concerned and should have no weight in deciding what has become of $\mathrm{M}_{4}$. That the above authors were in doubt is shown by the following foot-note taken from their paper: "With our present knowledge it is jmpossible to determine the way that vein $\mathrm{M}_{4}$ has disappeared in the Frenatæ. We have seen no indication that it coalesces with vein $\mathrm{Cu}_{1}$ as in Sthenopis, for in all pupæ of this suborder that we have examined the medial trachea is only three-branched. We are obliged, therefore, to omit any further reference to this vein in the discussion of this order." The venation of certain species of Hepialus is frequently abnormal. This is strikingly true of Hepialus humuli. I have seen wings which had extra branches on both media and radius. In the case of radius, specimens have been examined that contained six, seven, and even eight branches. So that the condition figured in the hind wing of Sthenopis is not unusual. The fact that none of the pupal wings showed any branching of this portion of the tracheæ of media in either wing and the further fact that Hepialus is one of the most generalized of lepidopterous insects, where of all places positive evidence should be sought for demonstrating this point, the interpretation must be, that the third branch of media in both wings, not only of Hepialus but of the Lepidoptera, is $\mathrm{M}_{3}+_{4}$.

Radio-Medial Cross-Vein.-The radio-medial cross-vein is distinct, in its usual place between $R_{5}$ and $M_{1}$, and is not preceded by a trachea.

Medial Cross-Vein.-The medial cross-vein is present, distinct, in its usual position between $M_{2}$ and $M_{3}$, and is not preceded by a trachea.

Cubitus. - The vein cavity of the cubitus of the front wings is located some distance behind the radio-medial vein cavity. It is free for a short distance at the base of the wing, then is 
fused with another vein to a point opposite the point of separation of media and radius. Here the cubitus bends abruptly toward the apex of the wing for a short distance and then turns abruptly again toward the wing margin, parallel with $\mathrm{M}_{4}$. Just before reaching the wing margin, it divides into $\mathrm{Cu}_{1}$ and $\mathrm{Cu}_{2}$. The basal part of the cubital trachea of all the front wings studied did not lie in the cubital vein but took a short cut toward the base of the wing. With the limited material at hand it is impossible to determine whether this is a normal condition or an artifact due to the mounting. The cubital vein cavity and trachea of the hind wing is situated much nearer to the medial trachea and vein cavity than in the front wing. The cubitus extends parallel to the media until near the wing margin where it divides into two branches, $\mathrm{Cu}_{1}$ and $\mathrm{Cu}_{2}$.

Medio-Cubital Cross-Vein.-The medio-cubital cross-vein is present, distinct, and in its usual position between $\mathrm{M}_{3}+_{4}$ and $\mathrm{Cu}_{1}$. This cross-vein differs from the other cross-veins in its oblique direction, a direction very suggestive that this was the course of the fourth branch of media. The entire lack of tracheæ in these veins defeats such an interpretation.

Arculus.--The arculus is a cross-vein-like structure at the base of the wing extending between radius and cubitus. The term arculus was first used for this structure in the wings of the Odonata, but as pointed out by Comstock and Needham, it is present in the wings of many insects. It is well developed in the wings of many Diptera but has not been pointed out hitherto in the wings of the Lepidoptera. The arculus, while crossvein-like, is in reality a compound structure. The stem of media passes to the base of the wing midway between radius and cubitus to the arculus, makes an abrupt bend to the front of the wing, forming the anterior portion of the arculus, extends to radius, and then makes another abrupt bend and extends to the base of the wing in combination with radius. The posterior part of the arculus is a true cross-vein, extending from the first abrupt bend of media to the cubitus. The anterior or median portion of the arculus may be designated as the anterior arculus $(a a)$ and the posterior part, consisting of a cross-vein as the posterior arculus $(p a)$.

Both front and hind wings of Hepialus thule show a well developed arculus. Practically all of the carefully prepared drawings of the wings of the Jugatæ give some hints as to the 
actual condition, though most of them indicate the media as coalesced at base with cubitus. An examination of the figures of the pupal wings of Hepialus thule shows the tracheæ of media lying along side the tracheæ of radius in the wing cavities of radius. A short distance from the base of the wing the median trachea diverges from the radial trachea into a broad vein cavity of its own, which passes obliquely across the wing for a short distance and then turns toward the margin of the wing between and parallel to the radial and cubital vein cavities and tracheæ. The oblique part of the median vein cavity is the anterior arculus $(a a)$. Near the point where the median trachea bifurcates, a broad vein cavity joins the median vein cavity and passes obliquely, posteriorly to the cubitus. This latter oblique vein cavity is not supplied with a trachea. It is the cross-vein part of the arculus, the posterior arculus $(p a)$. The posterior arculus of the front wing is much longer than that of the hind wing. This explains why in adult wings, the media frequently appears to be joined to the radius in the front wing and to the cubitus in the hind wing.

There is a great variation in the constituent parts of the arculus in the wings of different insects. This is especially true in the Diptera. A generalized condition is found in many wings, such as those of Tabanus or Leptis where the mecian vein joins the middle of the arculus. In such cases, the anterior arculus and the posterior arculus are subequal in length. Two lines of modification may be developed from this generalized condition. The media may migrate along the arculus nearer and nearer to the radius until it actually joins the radius. The anterior arculus through this migration becomes shorter and shorter, with a corresponding lengthening of the posterior arculus. When the media joins the radius, the anterior arculus is obliterated and the arculus is wholly cross-vein in structure or posterior arculus. If the posterior arculus atrophies in the descendants of such forms, the radius would appear to arise directly fron the radius without an abrupt bend. The second condition is found where the media migrates toward cubitus. There results a similar shortening of the posterior arculus and an elongation of the anterior arculus. This may proceed until the media is free from the arculus and coalesced with the cubitus as in the wings of Pantarbes or Erax. Whereas the cross-vein like structure was all cross-vein or posterior arculus in the first 
case, in the second case it is all median or anterior arculus. A similar atrophy of the anterior arculus may take place and a condition like that found in the wings of the muscids exist, where media appears to arise from cubitus. This shows how even in the two wings of the same species, as certain Jugatæ, the media may appear to arise from the radius in the front wings and from the cubitus in the hind wings.

Anal Veins.-The front wings of Hepialus thule has two anal veins, each represented by a trachea. The first anal vein is coalesced for a part of its course with the stem of cubitus. many figures of wings of Hepialus show a cross-vein between cubitus and the first anal vein, the cross-vein is the true course of cubitus. The apparent continuation of cubitus proximad of this cross-vein is the posterior arculus. The second anal vein lies close to the wing margin and the vein cavity is not well developed. The hind wing has three well developed anal tracheæ in three equidistant vein cavities. The vein cavity of the first anal vein is not so distinct as the others. 